\title{
Natural Adsorbents for Agricultural Waste Water Treatment
}

\author{
Neethu.P ${ }^{1}$, M.A Chinnamma ${ }^{2}$

\begin{abstract}
${ }^{1}$ Department of Environmental Engineering, Kerala Technical University, Thiruvanathapuram, India
\end{abstract} \\ ${ }^{2}$ Professor, Environmental Engineering, MCET Thrissur, Kerala, India
}

\begin{abstract}
In now a days, water problems have been one of the focus of great international concern and debate. Environmental pollution is mainly due to rapid industrialization. It is a demanding problem for maintaining the quality and cleanness of water. The discharges of industrial wastes in to aquatic bodies are a great threat to the aquatic life as well as for human health also. It is a matter of great importance due to their toxicity and after effects. Adsorption is an ecofriendly technique used now a days to treat the agricultural waste water. The sewage water is firstly filtered through suitable low cost and ecofriendly filter medias. Then the filtered water is subjected to adsorption using low cost and easily available natural adsorbents like banana peels and M. Thilapia fish scales. The combination of both these adsorbents was used for treatment of waste water with different proportion of height and contact time. The treated water obtained will have a considerable decrease in TDS, bacterial count, nitrogen content, Iron content, Potassium, TSS, turbidity, phosphorous, etc. as compared to initial characteristics of agro wastewater. This method is highly economic, cost effective and eco-friendly. This helps in reducing the water scarcity with the use of low cost adsorbents .
\end{abstract}

Keywords- BOD-Biochemical oxygen demand, CODChemical oxygen demand, TDS-Total dissolved solids, TSS-Total suspended solids, M.Thilapia-Mozambique Thilapia.

\section{INTRODUCTION}

India is a developing country with an increasing population day by day .In order to develop the economy, new industrial establishments are required. Much of the land and nearby water bodies are heavily polluted by haphazard dumping of solids and liquid wastes generated by rapid industrialization process. Increase in the amount of metal contents, inorganic and organic pollutants in to the environment are mainly due to failure of strict Environmental Laws in India Eco-toxicity effects living organisms due to polluted water sources have become a great concern for the last few decades. Heavy metal contents are one of the major classes of environmental pollutants that are found in the agro wastewater from the source of pesticides, chemicals etc. used for the plant growth. Removal of heavy metal contents and inorganic pollutants from effluents can be achieved by several methods. The recent technologies in use for waste water treatment have many major problems. High cost for construction of waste water treatment plants are highly uneconomical, space wastage, and they are commercially not pleasing in nature, with a much of disposal problems. These technologies are divided mainly into three major types specifically biological, physical and chemical. The recent technologies like electro floatation, electro kinetic coagulation, and coagulation combined with floatation and filtration, conventional oxidation methods by oxidizing agents, irradiation and electro chemical processes falls under chemical methods. These technologies are facing much disposal problems. Some methods like ion exchange and membrane process are quiet expensive. An alternative method is needed to overcome all these kinds of problems and to treat the waste water in more efficient way. The major advantage of using adsorption technique is that it gives the relevant level of energy saving from much efficient wastewater treatment system that is operating for less hours which is widely attractive because the biomass waste is inexpensive and is widely available. The complete bio sorption process requires the biological materials that have a very high metal binding properties and specific heavy metal selectivity. Adsorption process also works at low cost, the amount of chemical and biological sludge production is minimum, and there is no need of an additional nutrient requirement. Different adsorbents have been recently used for the removal of heavy metal contents. Few of them are rice straw, wood and bark, teawaste, sugarcane bagasse, tamarind hull, sawdust, rice husk, sunflower stem, banana peels, fish scales etc. Out of this banana peel is proved to be good for the treatment of diary waste water from the previous studies. Adsorbents prepared from dried banana peels have been proved effective for the removal of chromium, and copper ions from various aqueous solutions. The fish scales are used as the bio adsorbent for removal of copper, zinc and iron from the waste water. More amounts of these scales are generated from fish markets day by day which are thrown out as it is. This study reveals the significance of using an ecofriendly and pollution free outlook by using banana 
peels and fish scales for the treatment of agro waste water. Agricultural wastewater treatment is a farm management agenda for controlling pollution from surface runoff that may be contaminated by chemicals in fertilizer, pesticides, animal slurry, crop residues or irrigation water etc.

\section{MATERIALS AND METHODS}

\subsection{Materials}

Adsorbents used for the experimental works are banana peels and fish scales of M. thilapia.

\subsection{Methods}

Fresh banana peels were collected from domestic wastes, markets etc.as it is easily available. The peels were washed many times with tap water and is then followed by distilled water. The washed materials are then cut in to very small pieces and is allowed to dry at $80^{\circ} \mathrm{C}$ for 24 hours in a hot air oven. The moisture content was fully lost from it. The colour change was noticed from yellowish to brownish black. The dried material was then finely grounded and screened through the sieves size of $150-212 \mu \mathrm{m}$.In a similar manner, the fish scales were collected from the local fish market of city. Matured fish scales were washed thoroughly with fresh water to remove sticking dust and soluble pollutants from their surfaces. The fish scales were allowed to dry in sunlight for 2 days, till the scales become crispy. The dried scales were then converted into a size of $150-212 \mu \mathrm{m}$ in a mechanical grinder. Filtration is the physical water treatment technique. The filter media thus used should be efficient enough in treating water. The filter materials used are grass mulch, sandy soil and coarse aggregate. The filter medias used here are grass mulch, sand and coarse aggregate

\section{EXPERIMENTAL METHODS}

\subsection{Filtration tank}

The rectangular filtration tank is $0.45 \mathrm{~m}$ high, $0.3 \mathrm{~m}$ long and $0.25 \mathrm{~m}$ wide. The tank has a compartment of the filter medium where various filtering materials were placed.

\subsection{Adsorption column}

An apparatus of size $\mathrm{cm}$ length and $3.5 \mathrm{~cm}$ diameter is used and an overhead tank and collection tank is provided for this experiment. An outlet was provided at the bottom of the tank. Experiment is conducted by placing the adsorbents in column apparatus separately at first and then the combination of two adsorbents. From the overhead tank waste water is allowed to pass in to the apparatus, keeping suitable retention period with outlet closed, after the retention period open the outlet and collect the water from the collection tank. The collected water is then analyzed.

\section{RESULTS AND DISCUSSIONS}

The agricultural wastewater characteristics were tested before the commencement of the project and the various initial characteristics like $\mathrm{pH}, \mathrm{BOD}, \mathrm{COD}$, total suspended solids, total dissolved solids, alkalinity, chlorides, Dissolved oxygen, nitrogen, Phosphorous, iron, Potassium ,colour, turbidity etc. were tested and were compared with the potable water limit.

Table.1: Initial Characteristics of Waste Water.

\begin{tabular}{|l|c|c|}
\hline PARAMETERS & UNIT & $\begin{array}{c}\text { INITIAL } \\
\text { VALUE }\end{array}$ \\
\hline $\mathrm{pH}$ & - & 4.7 \\
\hline TSS & $\mathrm{Mg} / \mathrm{l}$ & 598 \\
\hline $\mathrm{COD}$ & $\mathrm{Mg} / \mathrm{l}$ & 164.0 \\
\hline $\mathrm{BOD}$ & $\mathrm{Mg} / \mathrm{l}$ & 48.0 \\
\hline Turbidity & $\mathrm{NTU}$ & 69.6 \\
\hline TDS & $\mathrm{Mg} / \mathrm{l}$ & 2409.0 \\
\hline E coli & $\mathrm{Mg} / 1$ & 2853 \\
\hline Colour & $\mathrm{Hazens}$ & 12.0 \\
\hline Iron & $\mathrm{Mg} / 1$ & 0.88 \\
\hline Potassium & $\mathrm{Mg} / 1$ & 32.8 \\
\hline Phosphorous & $\mathrm{Mg} / 1$ & 15.6 \\
\hline Nitrogen & $\mathrm{Mg} / 1$ & 38.4 \\
\hline
\end{tabular}

Table.2: Results obtained using in various time periods

\begin{tabular}{|l|c|c|c|}
\hline \multirow{2}{*}{ PARAMETERS } & \multicolumn{3}{|c|}{ HEIGHT IN 40 CM } \\
\cline { 2 - 4 } & 20min & 30min & 40min \\
\hline Ph & 5.8 & 5.9 & 6.1 \\
\hline Turbidity & 31 & 24 & 16 \\
\hline TSS & 198 & 154 & 125 \\
\hline TDS & 141 & 123 & 110 \\
\hline Iron & 0.41 & 0.4 & 0.37 \\
\hline Potassium & 7.4 & 4.1 & 2.3 \\
\hline Nitrogen & 16.5 & 15.2 & 14.1 \\
\hline Phosphorous & 7.1 & 4.3 & 2.2 \\
\hline Colour & 9 & 8 & 6 \\
\hline BOD & 29 & 26 & 24 \\
\hline COD & 126 & 124 & 122 \\
\hline E coli & 152 & 135 & 114 \\
\hline
\end{tabular}

The optimum time is obtained for the combination of both the adsorbents at a time period of $40 \mathrm{~min}$. This shows that the rate of adsorption increases with the increase in time. 


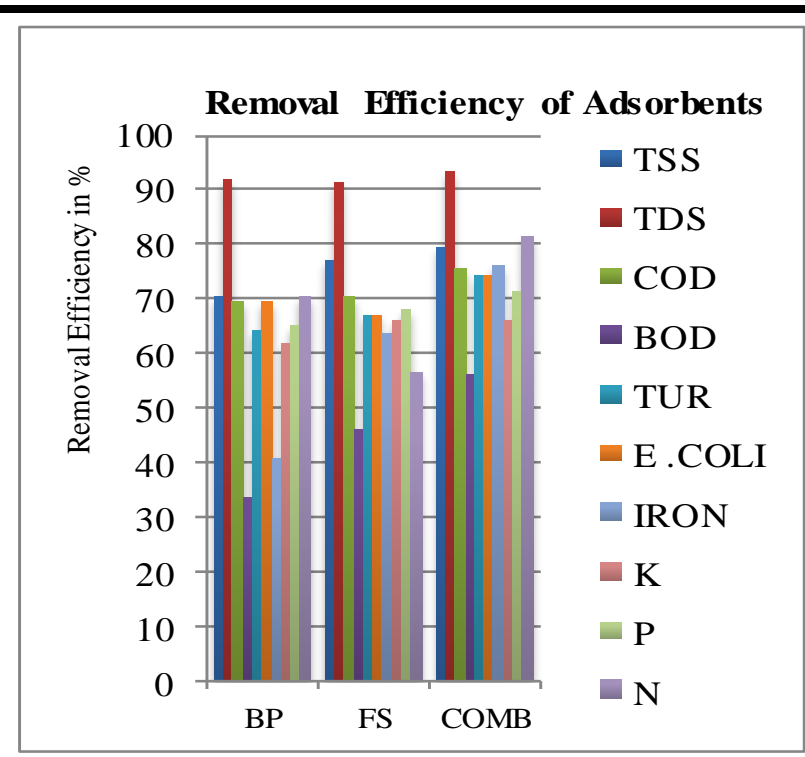

Chart.1: Removal Efficiency of Adsorbents

\section{CONCLUSIONS}

The various characteristics of agricultural wastewater were observed to be changed after the treatment with natural adsorbents. The $\mathrm{pH}$, and total nitrogen of the waste water sample were already only slightly above the safe limits. After the final treatment the values became much better. Later the dissolved and suspended solids, decreased after the treatment with natural adsorbents and the percentage of removal efficiency was above $90 \%$ and $71 \%$.The outstanding removal efficiency is obtained by using the combination of two adsorbents. Also there is a significant reduction in COD level. The turbidity removal efficiency is found to be greater than $73 \%$. The iron content was decreased considerably with an removal efficiency of above $76 \%$.From this we can conclude that the natural adsorbents plays an important role in the heavy metal removal and agro waste water treatment in the experiment. The $\mathrm{pH}$ value changed closer to normal $\mathrm{pH}$.The e coli count reduced to a great extent. Thus the water can be reused as irrigational water without any further treatment. The nitrogen, phosphorus, and potassium in the waste water sample tested, clearly revealed that the treated water can be used for the irrigational purpose of paddy plants and achieved a removal efficiency greater than 65\%.The colour of the treated water only shows little variation compared to the original waste water. From the experiment, it is observed that the water after treatment is fit for irrigation purposes, gardening, washing, cleaning and various other domestic purposes. Here the natural adsorbents proved to be more effective in water treatment. The results proved that the low cost adsorbents such as banana peel and fish scales can be fruitfully used for the removal of heavy metals too. The present study also revealed that the adsorption increases with increase in retention time and is dependent on the height of the adsorbent used in the adsorption column. Thus adsorption using low cost adsorbents like banana peel and fish scales open a new door to the existing water scarcity problem in Kerala. The outcome of agro waste water treatment using natural adsorbents is an answer to the existing problem of water scarcity and improved agriculture.Overall the project is found to be like take and put in use type.

\section{ACKNOWLEDGEMENTS}

The authors can acknowledge any person/authorities in this section. This is not mandatory.

\section{REFERENCES}

[1] A. V. Jamode et al. "Defluoridation of water using inexpensive adsorbents", J. Indian Inst. Sci., Sept.Oct. 2004, 84, pp. 163-171.2004

[2] Aadil Abbas et al.(2005) "Removal of Congo Red from Aqueous Solutions with Raphanus sativus peels and activated carbon: A Comparative Study",American-Eurasian J. Agric. \& Environ. Sci., 10 (5): 802-809, 2011, ISSN 1818-676.2005

[3] Abdel Majid ,Nassar, et al. "Purification of Storm water using Sand Filter", Journal of water Resources and Protection, November 2013, 5, 1007-1012.2013

[4] Adie D.B, et al. "Comparative Analysis of Filtration Using Corn Cob, Bone Char and Wood Chippings", International Journal of Applied Science and Technology Vol. 3 No. 3; March 2013.

[5] Aftab Begum, et al."Physico-chemical and fungal analysis of a fertilizer factory effluent", Nature of Environmental Pollution Technology, Vol.4(4), pp529-531.2005

[6] Alagumuthu. G. and Rajan. M (2010) "Equilibrium and kinetics of adsorption of fluoride onto zirconium impregnated cashew nut shell carbon". Chem. Eng. J., 158, p. 451-457, 2010.

[7] Alka Tapliyal,et al."Irrigation with domestic wastewater: Responses on growth and yield of ladyfinger Abelmoschus esculentus and on soil nutrients", Journal of Environmental Biology, (Impact Factor: 0.56). 09/2011; 32(5):645-51, September 2015. 